\title{
Hepatic Angiotensinogen Gene Regulation in the Fetal and Pregnant Rat $^{1}$
}

\author{
ALLEN D. EVERETT, ROBERT L. CHEVALIER, AND R. ARIEL GOMEZ
}

Department of Pediatrics, University of Virginia Health Sciences Center, Charlottesville, Virginia 22908

\begin{abstract}
To determine whether expression of the hepatic angiotensinogen (Ao) gene is modulated by 1) ontogeny, 2) pregnancy, 3) glucocorticoids, or 4) triiodothyroxine (T3), time-dated pregnant Wistar-Kyoto rats were studied at different gestational ages $(15,17$, and 20 d) without the influence of hormonal treatment or were given a daily intraperitoneal injection of dexamethasone (Dex) or T3 for $5 \mathrm{~d}$ (chronic Dex or T3) or a single injection of Dex (acute Dex). Maternal and fetal hepatic Ao mRNA levels were detected by dot and Northern blot analysis by using a full-length rat Ao cDNA. Fetal Ao mRNA levels were lower than in their maternal counterparts and lower than in adult rats of either sex. Maternal hepatic Ao mRNA levels were markedly diminished. mRNA levels were their lowest at $15 \mathrm{~d}$ of gestation and increased progressively as gestation advanced, reaching a peak at $\mathbf{2 0} \mathrm{d}$ of gestation. Chronic Dex treatment resulted in a $190 \%$ increase in maternal and a $370 \%$ increase in the fetal hepatic Ao mRNA levels. Acute Dex treatment resulted in a $260 \%$ increase in maternal hepatic Ao mRNA levels with no change in the fetus. Hepatic Ao mRNA levels increased to the nonpregnant level with acute and chronic Dex treatment. Chronic T3 treatment resulted in a $20 \%$ increase in maternal hepatic Ao mRNA levels, without alteration of fetal Ao gene expression. We conclude that 1) the fetal and pregnant state results in a profound decrease in maternal and fetal hepatic Ao gene expression, 2) Ao gene expression is regulated by glucocorticoids in the term fetal and maternal liver, and 3) chronic T3 treatment results in a modest increase in maternal hepatic Ao gene expression. (Pediatr Res 30: 252-255, 1991)
\end{abstract}

\section{Abbreviations}

Ao, angiotensinogen

T3, L-triiodothyronine

Dex, dexamethasone

WKY, Wistar-Kyoto

${ }^{32} \mathbf{P}$, phosphorous 32

All components of the circulating renin-angiotensin system are present in the adult, newborn, and maturing fetus $(1-3)$. The prohormone Ao serves as substrate for the renin-angiotensin

Received November 9, 1990; accepted May 10, 1991.

Correspondence and reprint requests: R. Ariel Gomez, M.D., University of Virginia Health Sciences Center, Department of Pediatrics, MR-4 Building, Rm 2010, Charlottesville, VA 22908.

Supported by American Heart Association Grant-In-Aid No. 86104 (R.A.G.) and NIH Grants R01HL41899 and IK04HL02307. R.L.C. is supported by NIH Grants R01HL40209 and R01DK40558. A.D.E. is the recipient of an American Heart Association, Virginia Affiliate Fellowship No. 880014 . R.A.G. is the recipient of a Syntex Scholars Award from Syntex Corporation.

${ }^{1}$ Presented in part at the annual meeting of the Southern Society for Pediatric Research, February 2, 1989. cascade and, as such, is the only known precursor of the vasoactive hormone angiotensin II. We have recently demonstrated that angiotensinogen gene expression is developmentally regulated in a tissue-specific manner with hepatic angiotensinogen mRNA levels markedly lower in the fetus than in the newborn or adult (4). Whereas aspects of the regulation of angiotensinogen gene expression have been partially studied in the adult animal (5-8), the mechanisms regulating angiotensinogen gene expression in the fetal or pregnant rat have not been previously investigated.

The present study was designed to investigate the response of the fetal and pregnant rat hepatic angiotensinogen gene to the pregnant state, glucocorticoid, and $\mathrm{T} 3$ administration.

\section{MATERIALS AND METHODS}

Animal preparation. Twenty-nine time-dated pregnant WKY rats (Charles River Breeding Laboratories, Inc., Boston, MA) were housed at the University of Virginia Vivarium in opaque polypropylene cages with standard Rat Chow (Purina 5012; Ralston-Purina, St. Louis, MO) and tap water available ad libitum throughout the study. Animal quarters were air-conditioned and had a 12-h light/dark cycle with lights on at $0800 \mathrm{~h}$.

Effect of pregnancy on maternal hepatic Ao gene expression. Nine time-dated pregnant WKY rats were divided into groups of three and were killed on d 15, 17, and 20 of gestation. Maternal livers were immediately removed, frozen in liquid nitrogen, and stored at $-70^{\circ} \mathrm{C}$ until processed for Ao mRNA determinations.

Effect of acute and chronic Dex and T3 on fetal and maternal hepatic Ao gene expression. Chronic studies were performed starting at $\mathrm{d} 15$ of gestation. The pregnant rats were divided into groups receiving either no treatment (control, $n=3$ ) or a daily intraperitoneal injection with saline vehicle (vehicle, $n=3$ ), Dex phosphate (Elkins-Sinn, Cherry Hill, NJ) $10 \mathrm{mg} / \mathrm{kg}(n=3)$, or $10 \mu \mathrm{g} / \mathrm{kg}$ of T3 (Sigma Chemical Co., St. Louis, MO) $(n=2)$ each morning for 5 consecutive days. On the morning of $20 \mathrm{~d}$ of gestation, the animals were given intraperitoneal injections of sodium pentobarbital and were killed by decapitation. Maternal and fetal livers were rapidly removed, frozen in liquid nitrogen, stored at $-70^{\circ} \mathrm{C}$, and processed as described above. A total of 99 fetuses and 11 adult rats were examined. Fetal tissues from each litter were pooled to determine the biologic mean for fetal Ao mRNA.

For acute experiments, time-dated WKY rats on d 20 of gestation were given either a single intraperitoneal injection of vehicle (saline) $(n=5)$ of $10 \mathrm{mg} / \mathrm{kg}$ of Dex $(n=5)$ and killed as described above after $6 \mathrm{~h}$. Maternal and fetal livers were removed and processed as described above. A total of 74 fetuses and 10 adult rats were examined. Fetal tissues from each litter were pooled as described above.

Extraction, electrophoresis, and hybridization of RNA to complementary DNA. RNA was extracted by the method of Chirgwin et al. (9). RNA concentrations were determined spectrometrically at $260 \mathrm{~nm}$. Electrophoresis and hybridization of RNA was performed as previously described (4). Briefly, RNA was denatured 
by heating for $10 \mathrm{~min}$ at $65^{\circ} \mathrm{C}$ in $4.4 \mathrm{M}$ formaldehyde- $50 \%$ formamide and resolved by electrophoresis on a $1.0 \%$ agarose gel containing $2.2 \mathrm{M}$ formaldehyde. The RNA was transferred to a positively charged nylon 66 membrane (Zetabind; AMF Cuno, Meriden, CT) by capillary action (Northern blot). The bound RNA was heated in vacuo at $80^{\circ} \mathrm{C}$ for $1 \mathrm{~h}$, exposed to UV light from an UV transilluminator $\left(254 \mathrm{~nm}, 500 \mu \mathrm{W} / \mathrm{cm}^{2}\right)$ for 1 min, dried, and stored until hybridized as described below.

Dot blots were prepared by dissolving $1.00-0.125 \mu \mathrm{g}$ total RNA in $0.5 \mathrm{~mL}$ of sterile $25 \mathrm{mM}$ sodium phosphate buffer (pH 7.2) and applying this RNA to a Zetabind membrane preequilibrated with the same buffer.

Dot and Northern blots were hybridized by the method of Church and Gilbert (10) with a full-length (1.6-kb) rat Ao cDNA (gift of Dr. K. Lynch, University of Virginia) labeled with ${ }^{32} \mathrm{P}$ by nick translation (11) as we previously described (4). Signals were detected by autoradiography by using an intensifying screen with multiple exposures made within the linearity of Kodak AR and RP film. Messenger RNA determinations were performed by laser densitometry (LKB Laser Densitometer, Bromma, Sweden) with each well scanned three times, and the average absorbance was expressed as a percentage of increase or decrease between groups. All densitometric comparisons between groups were from the same autoradiograph. Northern blots were performed in parallel with dot blots to confirm the lack of RNA degradation.

As a control for RNA degradation and to confirm whether observed differences in Ao mRNA acumulation were gene specific, Northern blots were performed in duplicate and were also hybridized to a $\beta$-actin cDNA prepared from a rat aorta DNA library (a gift of Dr. Gary Owens and Marcie Corjay, University of Virginia).

\section{RESULTS}

All maternal and fetal hepatic RNA samples were intact and possessed the correct electrophoretic mobility without degradation as demonstrated by comparable hybridization to $\beta$-actin cDNA in the experimental and control groups. In addition, $\beta$ actin gene expression was unaltered by Dex treatment or pregnancy in the maternal or fetal groups (data not shown).

Effect of pregnancy on maternal hepatic Ao gene expression. The expression of maternal hepatic Ao mRNA changed markedly throughout the last third of gestation (Fig. 1). Hepatic Ao mRNA levels in untreated pregnant rats were markedly decreased at $15 \mathrm{~d}$ gestation $(15 \mathrm{D})$, with levels gradually increasing at $17 \mathrm{~d}$ gestation $(17 \mathrm{D})$ to maximal levels at $20 \mathrm{~d}$ gestation $(20$

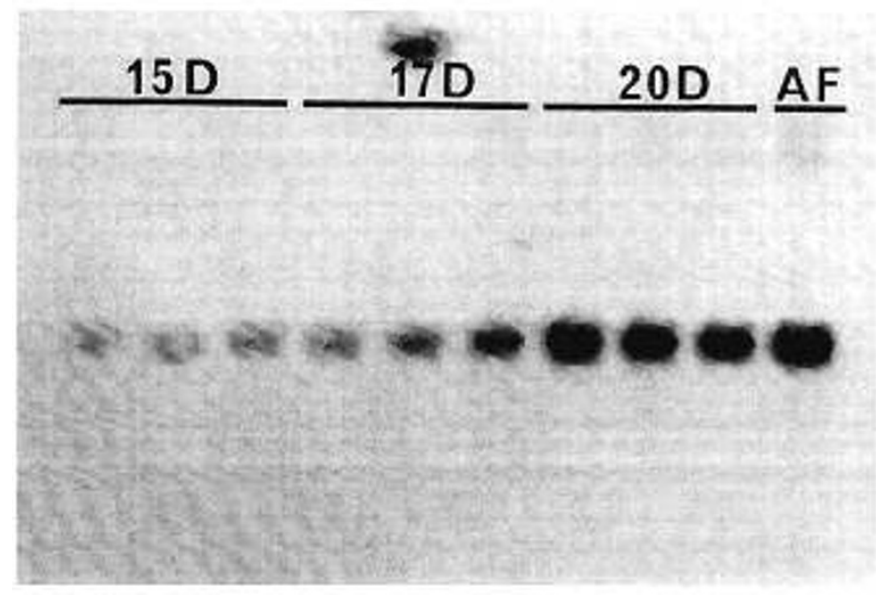

Fig. 1. Representative Northern blot of maternal hepatic angiotensinogen mRNA accumulation at different gestational ages. $15 D, 15 \mathrm{~d}$ of gestation; $17 D, 17 \mathrm{~d}$ of gestation; $20 D, 20 \mathrm{~d}$ of gestation; $A F$, adult nonpregnant female. Each lane represents a single animal with $5 \mu \mathrm{g}$ of total hepatic RNA placed in each lane. Exposure of $3 \mathrm{~d}$, with an intensifying screen on Kodak AR film.
$D$ ). In addition, maternal hepatic Ao mRNA levels were markedly lower than Ao mRNA levels in the adult nonpregnant female ( $A F$, Fig. 1) or in the adult male ( $A M$, see Fig. 2). Thus, pregnancy appears to result in a profound downregulation in Ao gene expression during the last third of gestation.

Effect of ontogeny. As demonstrated by Figures $2 B$ and $3 B$, during fetal life hepatic Ao mRNA is barely detectable by Northern analysis and, regardless of the treatment status, fetal Ao mRNA levels were always lower than maternal levels or those observed in adult rats of either sex (Figs. $2 A$ and $B$ and $3 A$ and $B)$. Therefore, during fetal life, there is a profound reduction in hepatic Ao gene expression.

Effect of chronic Dex and T3 on maternal and fetal Ao gene expression. The response of maternal and fetal Ao mRNA levels to Dex and T3 are shown in Figure 2. The dot blot analysis of Figure $2 A$ demonstrates that chronic Dex administration resulted in increased hepatic Ao mRNA levels in both the maternal and fetal livers $(D)$. Densitometric analysis demonstrated a $190 \%$ increase in maternal and a $370 \%$ increase in fetal hepatic Ao levels. T3 $(T)$ treatment increased maternal hepatic Ao gene expression $20 \%$, although fetal gene expression was not altered. Regardless of the treatment status, fetal Ao mRNA levels were always lower than maternal levels. As shown in Figure $2 B$, fetal liver Ao mRNA at term is barely detectable by Northern analysis even with chronic Dex stimulation.

Effect of acute Dex on maternal and fetal Ao gene expression. To determine if the maternal and fetal hepatic Ao gene response to Dex was a time-related phenomenon, the maternal and fetal hepatic response to acute Dex administration at $20 \mathrm{~d}$ of gestation is shown in the dot blot of Figure $3 \mathrm{~A}$. Acute Dex administration increased maternal hepatic Ao mRNA by $260 \%$ when compared
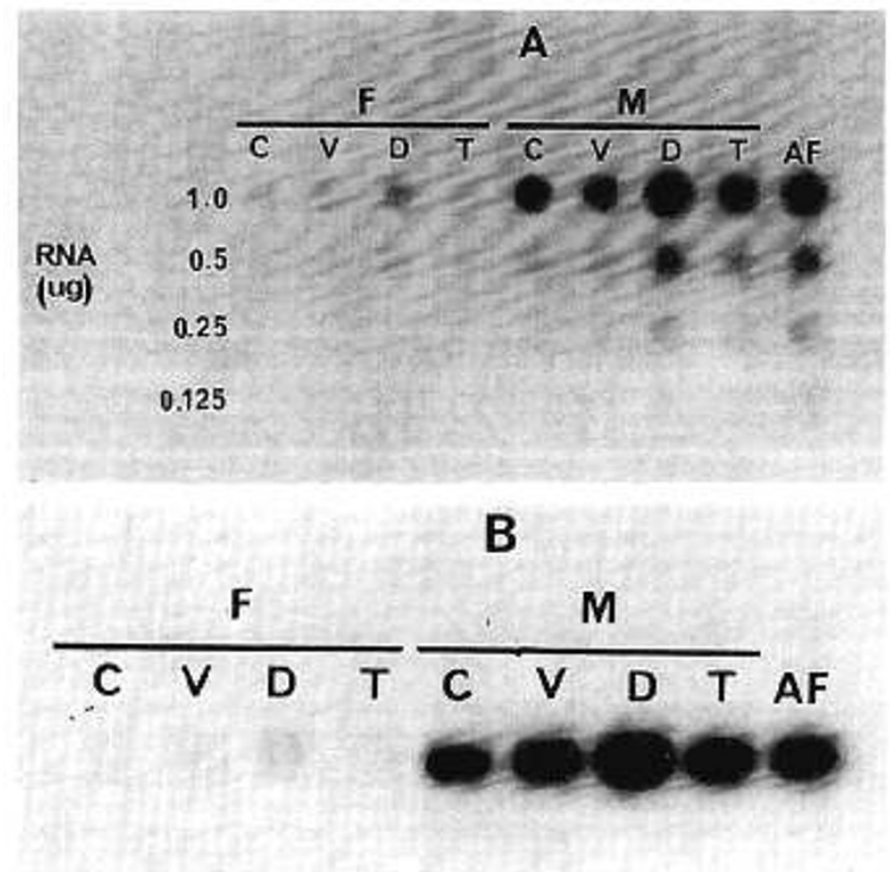

Fig. 2. $A$, Maternal $(M)$ and fetal $(F)$ hepatic accumulation of Ao mRNA with chronic Dex $(D)$ and T3 $(T)$ treatment. Total RNA was serially diluted $(1.0-0.125 \mu \mathrm{g})$ as indicated by the vertical numbers and placed in each well. The horizontal row indicates the control group $(C)$, vehicle-treated group $(V)$, and total hepatic RNA from an adult virgin female $(A F)$. Exposure of $14 \mathrm{~h}$ with Kodak RP film and an intensifying screen. Number of animals: one per lane for the maternal, and the corresponding fetal livers were pooled: 12 control, 11 vehicle, 10 Dex, $13 \Upsilon 3$. $B$, Companion Northern blot of maternal and fetal hepatic angiotensinogen mRNA with chronic Dex and T3 treatment. Total RNA $(5 \mu \mathrm{g})$ were placed in each lane. Exposure time of $14 \mathrm{~h}$ with Kodak RP film with an intensifying screen. Abbreviations are as described for $A$. 

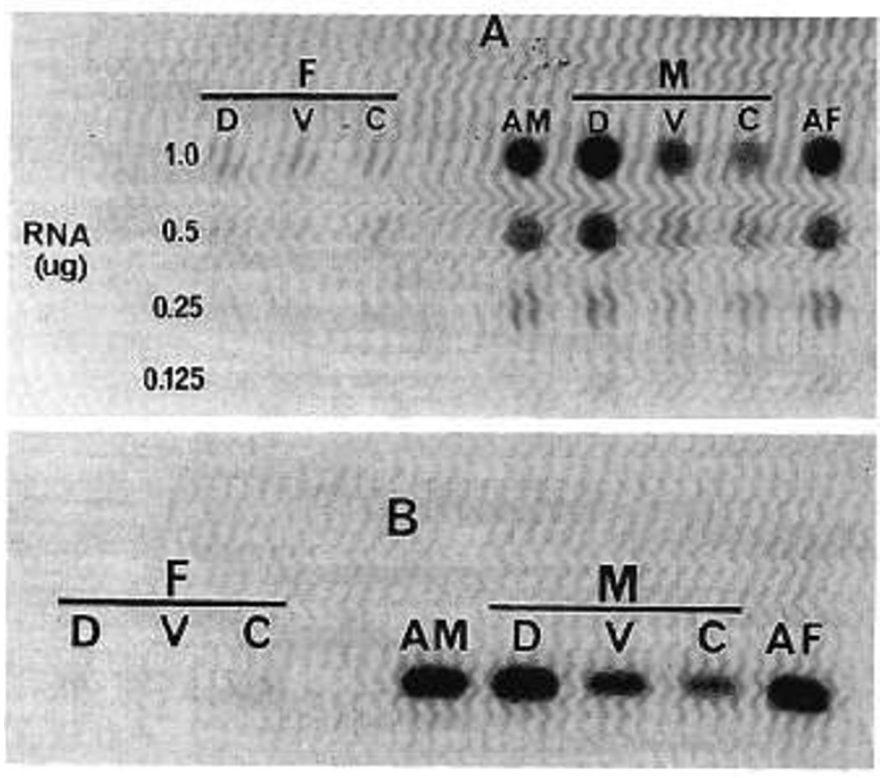

Fig. 3. $A$, Effect of acute Dex $(D)$ and various physiologic conditions on maternal $(M)$ and fetal $(F)$ hepatic accumulation of Ao mRNA. Total hepatic RNA was serially diluted (1.0-0.125 $\mu \mathrm{g})$ and placed in each well as indicated by the vertical numbers. The horizontal letters represent vehicle treatment $(V)$, control $(C)$, adult male $(A M)$, and adult virgin female $(A F)$. Number of animals: one for maternal, and the corresponding fetal livers were pooled; 11 control, 12 vehicle, 12 Dex. Exposure of $12 \mathrm{~h}$ with Kodak RP film with an intensifying screen. $B$, Companion Northern blot of total maternal and fetal hepatic RNA with acute Dex treatment. Total RNA $(5 \mu \mathrm{g})$ was loaded in each lane. Exposure time of $12 \mathrm{~h}$ with Kodak RP film and an intensifying screen. Abbreviations as described for $A$.

with vehicle-treated rats. However, acute Dex administration induced no changes in fetal Ao mRNA concentration ( $D$ versus V).

\section{DISCUSSION}

The present study demonstrates the following points. 1) Expression of the hepatic Ao gene is lower in the fetal rat than in the adult male, virgin female, or pregnant rat. 2) Despite low basal levels of expression, the Ao gene is regulated by Dex in the term fetus. 3) During pregnancy, maternal hepatic Ao gene expression is reduced. However, the maternal liver is more responsive than the fetal liver to acute Dex stimulation. 4) The maternal Ao gene is modestly responsive to T3.

As we previously reported, hepatic Ao mRNA levels are lower during fetal life than at any other time point during ontogeny, increasing to adult levels dramatically within $24 \mathrm{~h}$ of birth (4). The present study confirms and extends those observations, demonstrating that fetal Ao gene expression at term is also markedly less than in the pregnant, nonpregnant female, and male adult animals. The reasons for the differences between fetal and adult Ao mRNA levels are not clear. Because fetal Ao mRNA increased rapidly hours after birth, we postulated that some of the complex neurohumoral changes surrounding partuition and/ or extrauterine life may have influenced the expression of fetal hepatic Ao gene (4). Among possible hormonal influences, we postulated that steroid and thyroid hormones known to increase around the time of birth may stimulate fetal Ao gene expression (4).

Steroid hormones exert their effects by intracellular glucocorticoid receptor coupling; the receptor-ligand complex then interacts with specific target DNA and modulates transcription of selected genes (12). The Ao gene, as described by Ohkubo et al. (8), possesses homology with glucorticoid receptor-binding sequences in the $5^{\prime}$-flanking region and thus provides a basis for possible glucocorticoid regulation of the Ao gene. Those authors and others have demonstrated that Dex administration to adult rats results in an increase in liver Ao mRNA (5-8). In the present study, we demonstrated that Dex significantly increased maternal and fetal hepatic Ao mRNA levels with chronic administration but only the maternal liver acutely. Previous investigators have demonstrated that cellular sensitivity to glucocorticoids is affected by receptor concentration but may also be altered by the presence of nonfunctional or modified receptors or by other cellular factors that modify receptor interactions with target genes (13). The action of Dex in the mother and fetus is most likely via active glucocorticoid receptors (14); other factors (such as directly altered posttranscriptional modification of mRNA) are possible but less likely. Active cytosolic glucocorticoid receptors have been described in multiple organs in the fetal, newborn, and adult rat (15-17). Although present in sufficient quantities at term, fetal hepatic glucocorticoid receptors appear to demonstrate differential affinity for ligand binding and possible receptor heterogeneity when compared with those of the adult $(15,18$, 19). Therefore, the difference in maternal and fetal hepatic responses at term to acute Dex stimulation could possibly be because of altered responsiveness and heterogeneity of fetal glucocorticoid receptors and/or limited ligand-receptor coupling to the fetal hepatic Ao gene. Although the lack of fetal response to acute Dex could be ascribed to decreased uptake or altered metabolism of Dex by the fetus, acute s.c. administration of 2 $\mathrm{mg} / \mathrm{kg}$ of Dex has previously been shown to rapidly enter the fetal compartment as reflected by a decrease in ornithine decarboxylase activity as early as $4 \mathrm{~h}$ after administration (20). Thus, we speculate that prolonged exposure to increased glucocorticoids (chronic treatment) results in improved efficiency of receptor-ligand binding and/or enhanced receptor-ligand-DNA interactions to increase gene transcription or gene product stabilization.

Thyroid hormones are known to increase production and secretion of Ao from liver slices (21), and, in the Reuber H35 rat hepatoma cell line, the increase in Ao production and secretion is associated with an increase in Ao mRNA (14). In the present study, unlike Dex, chronic administration $(5 \mathrm{~d})$ of T3 modestly increased maternal hepatic Ao mRNA accumulation without altering fetal hepatic Ao gene expression. As previously demonstrated, the placenta is relatively impermeable to T3 and thyroxine $(22,23)$. Thus, the lack of fetal response is most likely related to the inability to significantly increase circulating T3 in the fetus. In the intact adult animal, the hepatic Ao gene is poorly responsive to T3 alone. Sernia et al. (24) by using adult male rats, also demonstrated only a $20 \%$ increase in hepatic mRNA after $10 \mathrm{~d}$ of T3 treatment. Although T3 alone induces a small increase in Ao mRNA levels, as others have suggested, T3 may act primarily in a permissive fashion to enhance the action of other hormones such as glucocorticoids (14). Further studies are necessary to determine the effect of T3 on fetal Ao gene expression.

Ao gene regulation during pregnancy has not been previously described. In the present study, we determined that hepatic Ao mRNA concentrations are reduced in the pregnant rat, when compared with the adult nonpregnant female or male rat, and are gestationally regulated. Although Ao mRNA concentrations were decreased, the Ao gene was still responsive to Dex. Previous investigators have demonstrated that circulating levels of Ao and renin are increased during pregnancy $(25,26)$. The elevation of estrogens during pregnancy has been proposed as an explanation for the increase in circulating Ao levels $(26,27)$, implying an estrogen-mediated increase in Ao gene expression and synthesis. Although we did not obtain serum Ao levels as a comparison, we report that Ao gene expression is reduced with pregnancy at every day of gestation studied. The discrepancy between decreased gene expression and circulating Ao levels could be explained by the identification of multiple circulating forms of Ao during pregnancy (27); at least one of the these Ao isoforms may 
have altered kinetics for renin (27). Altered clearance of these multiple isoforms could possibly explain the descrepancy between high circulating Ao levels and low Ao mRNA expression. In addition, it is possible that alternate sources of Ao (such as placenta) may contribute to high levels of Ao seen during pregnancy. Further studies are needed to delineate the mechanisms regulating Ao gene expression during pregnancy and their potential impact on maternal hemodynamic regulation.

In conclusion, the rat maternal and fetal hepatic Ao gene can be regulated by glucocorticoids at term, possibly via active glucocorticoid receptors. This ability to enhance Ao gene expression with glucocorticoids in the fetal rat suggests an important role for Ao even during fetal life, possibly by mediating hemodynamic homeostasis and preparing the fetus for the transition to extrauterine life. The present study represents the first report of gestational regulation of maternal hepatic Ao gene expression. The mechanisms involved in the disproportionate downregulation of Ao gene expression and the reported increased circulating Ao activity during pregnancy are unknown and are under further investigation. Further studies are needed to determine the homeostatic regulation of Ao and renin during pregnancy and their impact on cardiovascular control.

\section{REFERENCES}

1. Gomez RA, Chevalier RL, Sturgill B, Johns DW, Peach MJ, Carey RM 1986 Maturation of the intrarenal renin distribution in Wistar-Kyoto (WKY) rats. J Hypertens 4 (suppl 5):S31-S33

2. Levens N, Peach MJ, Carey RM 1981 Role of the intrarenal renin-angiotensin system in the control of renal function. Circ Res 48:157-167

3. Navar LG, Rosivall L 1984 Contribution of the renin-angiotensin system to the control of intrarenal hemodynamics. Kidney Int 25:857-868

4. Gomez RA, Cassis L, Lynch KR, Chevalier RL, Wilfong N, Carey RM, Peach MJ 1988 Fetal expresion of the angiotensinogen gene. Endocrinology 123:2298-2302

5. Campvell D, Habener J 1985 Angiotensinogen gene is expressed and differentially regulated in multiple tissues of the rat. J Clin Invest 78:31-39

6. Kalinyak J, Perlman A 1987 Tissue specific regulation of angiotensinogen mRNA accumulation by dexamethasone. J Biol Chem 262:460-464

7. Kumapuli S, Benedict L, Kumar A 1987 Tissue specific hormonal regulation of the rat angiotensinogen gene expression. Arch Biochem Biophys 254:642646
8. Ohkubo H, Nakayana K, Tanaka T, Nakanishi S 1986 Tissue distribution of rat angiotensinogen mRNA and structural analysis of its heterogeneity. J Biol Chem 261:319-323

9. Chirgwin JM, Przbyla AE, Macdonald RJ, Rutter WJ 1979 Isolation of biologically active ribonucleic acid from sources enriched in ribonuclease. Biochemistry 18:5294-5299

10. Church GM, Gilbert W 1974 Genomic sequencing. Proc Natl Acad Sci USA 81:1991-1995

11. Rigby WD, Dieckmann M, Rhodes C, Berg P 1977 Labeling deoxyribonucleic acid to high specific activity in vitro by nick-translation with DNA polymerase I. J Mol Biol 113:237-251

12. Burnstein KL, Cidlowski JA 1989 Regulation of gene expression by glucocorticoids. Annu Rev Physiol 51:683-699

13. Gustafsson J-A, Carlstedt-Duke J, Poellinger L, Okret L, Wikstrom A-C 1987 Biochemistry, molecular biology, and physiology of the glucocorticoid receptor. Endocr Rev 8:185-234

14. Chang E, Perlman AJ 1987 Multiple hormones regulate angiotensinogen messenger ribonucleic acid levels in rat hepatoma cell line. Endocrinology 121:513-519

15. Feldman D 1974 Ontogeny of rat hepatic glucocorticoid receptors. Endocrinology 95:1219-1227

16. Kalami M 1984 Glucocorticoid receptors: from development to aging. A review. Mech Ageing Dev 24:129-138

17. Kitraki E, Alexis MN, Stylianopoulou F 1984 Glucocorticoid receptors in developing rat brain and liver. Biochemistry 20:263-269

18. Giannopoulos $G 1975$ Ontogeny of glucocorticoid receptors in rat liver. J Biol Chem 250:5847-5851

19. Kalimi M, Gupta S 1982 Physicochemical characterization of rat liver glucocorticoid receptor during development. J Biol Chem 257:13324-13328

20. Navarro HA, Lachowicz J, Bartolome J, Whitmore WL, Slotkin TA 1988 Effects of prenatal dexamethasone on development of ornithine decarboxylase activity in brain and peripheral tissues of rats. Pediatr Res 24:465-469

21. Dzau VJ, Herrmann HC 1982 Hormonal control of angiotensinogen production. Life Sci 30:577-587

22. Cuestas RA 1978 Thyroid function in healthy premature infant. J Pediatr 92:963-967

23. Fisher DA 1964 Placental transport of thyroxine. J Clin Endocrinol Metab 24:393-400

24. Sernia C, Clements JA, Funder JW 1989 Regulation of liver angiotensinogen mRNA by glucocorticoids and thyroxine. Mol Cell Endocrinol 61:147-156

25. Derkx FHM, Stuenkel C, Schalekamp MPA, Visser W, Huisveld IH, Schalekamp MADH 1986 Immunoreactive renin, prorenin, and enzymatically active renin in plasma during pregnancy and in women taking oral contraceptives. J Clin Endocrinol Metab 63:1008-1015

26. Tetlow HJ, Broughton-Pipkin F 1986 Changing renin substrates in human pregnancy. J Endocrinol 109:257-262

27. Daniels CR, Eisen V, Slater JDH 1987 The renin-angiotensinogen reaction during pregnancy and oral contraception: estimation of kinetic parameters by an autologous plasma renin assay. J Endocrinol 112:465-472 